\title{
Dual-route processing of complex words: New fMRI evidence from derivational suffixation
}

\author{
JENNIFER VANNEST \\ University of Rochester, Rochester, New York \\ and \\ THAD A. POLK and RICHARD L. LEWIS \\ University of Michigan, Ann Arbor, Michigan
}

\begin{abstract}
Many behavioral models of the comprehension of suffixed words assume a dual-route mechanism in which these words are accessed sometimes from the mental lexicon as whole units and sometimes in terms of their component morphemes (such as happi+ness). In related neuropsychological work, Ullman et al. (1997) proposed a dual-route model for past tense processing, in which the lexicon (used for access to irregularly inflected forms) corresponds to declarative memory and a medial temporal/ parietal circuit, and the rule system (used for computation of regularly inflected forms) corresponds to procedural memory and a frontal (including Broca's area)/basal ganglia circuit. We used functional MRI and a memory encoding task to test this model for derivationally suffixed words, comparing those words that show evidence of decompositional processing in behavioral studies (-ness, -less, and -able words) with derived words that do not show decomposition effects (-ity and -ation words). By examining Broca's area and the basal ganglia as regions of interest, we found that "decomposable" derived and inflected words showed increases in activity relative to nondecomposable suffixed words. Results support a dual-route model of lexical access of complex words that is consistent with the Ullman et al. proposal.
\end{abstract}

When readers process a complex word, is it accessed from the mental lexicon as a whole word or as a collection of separable morphemes? Because prefixes and suffixes are frequent, productive, and relatively invariant forms in language, it is possible that mental representations might take advantage of this invariance by representing morphemes as separable units. In behavioral experimental work, however, effects of morphological structure on word reading are not always detected. Models of this process (Caramazza, Laudanna, \& Romani, 1988; Schreuder \& Baayen, 1995) suggest a dual-route mechanism in which affixed words are sometimes accessed as whole units, sometimes as component morphemes (this second process is referred to as morphological decomposition or computation). Recently, neural correlates of a dual-route mechanism have been investigated, but solely for inflected words, and particularly for the past tense (see Beretta et al., 2003; Jaeger, Van Valin, \& Lockwood, 1998). By looking at derived words, this study offers further evidence based on a recent model of linguistic processing in the brain (Ullman, 2001; Ullman et al., 1997) for

This study was supported by a pilot study grant from the University of Michigan Functional MRI Center. The authors thank Michael Ullman and three anonymous reviewers for detailed comments. Thanks to Laura Cechanowicz and Mason Smith for help with data analysis, and to Lee Wurm and Maya Khanna for comments on an earlier version of the article. Correspondence related to this article may be sent to J. Vannest, Brain and Cognitive Sciences, University of Rochester, Meliora Hall, Box 270268, Rochester, NY 14627 (e-mail: jvannest@bcs.rochester.edu). differing patterns of neural activity corresponding to whole-word and decompositional processing routes.

Whether a complex word is processed decompositionally seems to depend on the linguistic properties of the affix it includes. Regular inflectional suffixes, such as English past tense, Finnish case inflections, and the Dutch regular plural, serve a grammatical function without changing the meaning or part of speech of words to which they attach, and they consistently show evidence of morphological decomposition in behavioral studies (Alegre \& Gordon, 1999; Niemi, Laine, \& Tuominen, 1994). A subset of derivational suffixes, or of suffixes that do change meaning and part of speech, shows a similar pattern: For instance, suffixes like English -ness and -able or Dutch -heid show evidence of decompositional processing (Bertram, Schreuder, \& Baayen, 2000; Vannest, Bertram, Jarvikivi, \& Niemi, 2002). These suffixes do not change the pronunciation of the base words to which they attach and are relatively productive and consistent in meaning. A different pattern, however, is found for words with derivational suffixes that can indeed change the form of base words to which they attach (e.g., serene $\rightarrow$ serenity). These suffixed words seem to be processed as wholeword units rather than as individual morphemes (Bradley, 1980; Vannest \& Boland, 1999). This pattern holds even for idiosyncratic items in which these "whole-word processed" suffixes do not produce a phonological change (e.g., obese $\rightarrow$ obesity; see Vannest \& Boland, 1999).

The empirical evidence for this division among suffix types is largely based on the observed effects of fre- 
quency on response times to the suffixed words. Specifically, response times to suffixed words may be affected by how frequently a particular base and suffix occur together (surface frequency), as well as by how frequently the base morpheme occurs in any word form (base frequency). In the original test of such effects, Taft (1979) compared lexical decision times for high-base-frequency words with those for low-base-frequency words. The study included both inflected and derived words, and all words were matched for surface frequency. Taft suggested that if the morphemes in the affixed words were being accessed separately, base frequency would have an effect on response times in a lexical decision task. Base frequency would not be a relevant variable, however, if affixed words were being accessed as whole-word units. Taft's results confirmed the prediction of the decomposition model: Words with high base frequency were responded to more quickly than those with low base frequency. Bradley (1980) used a frequency-contrast design similar to Taft's but refined the choice of stimuli to focus on specific derivational suffixes in English (-ness, -er, -ment, and -ion). Bradley found that for sets of words with the first three suffixes, differences in surface frequency and base frequency both affected lexical decision time, but for -ion words, only surface frequency had an effect. Bradley suggested that phonologically neutral suffixes (i.e., those that do not make phonological changes to the words to which they attach) are accessed from the lexicon separately from their corresponding roots, whereas words with nonneutral suffixes (which allow phonological interaction between root and suffix) are accessed as whole units. Results from Vannest and Boland (1999) supported this claim. They found base frequency effects in lexical decision for words with the phonologically neutral, productive derivational suffix -less, which suggested morphological decomposition. They did not find such effects for derivations with the suffixes -ity and -ation, however, suggesting that these words are accessed from the lexicon as full forms. ${ }^{1}$ Surface frequency effects were found for both word types. The claim that some complex words are accessed via component morphemes and some as full forms has been instantiated in dual-mechanism processing models (e.g., Schreuder \& Baayen, 1995) that account for these observed differences in base and surface frequency effects.

The assumption that base frequency effects are evidence of morphological decomposition during lexical access may certainly be called into question. Approaches to morphological processing based on the connectionist model of visual word recognition (see Joanisse \& Seidenberg, 1999; Raveh, 2002; Rueckl, Mikolinski, Raveh, Miner, \& Mars, 1997; Rueckl \& Raveh, 1999; Seidenberg \& Gonnerman, 2000) assume that a single system supports processing of both monomorphemic and complex words and that no decomposition takes place. Morphological relationships between words, according to these models, result from overlap in the orthographic, phonological, and semantic properties of the words. For example, Joanisse and Seidenberg (1999) proposed such a model for past tense inflection: Because regularly suffixed $(-e d)$ past tense forms have a great deal of phonological overlap with their base forms, phonology plays a role in accessing these past tense forms. Irregular past tenses (e.g., go $\rightarrow$ went) do not show as much phonological overlap with their base forms, and therefore semantic information plays a greater role in accessing these past tenses. In this framework, base frequency effects also result from connections between base words and suffixed forms that may overlap, with varying degrees of orthographic, phonological, and semantic similarity. For example, responses to agreeable are facilitated by the frequency of agree more than responses to serenity are by the frequency of serene, not because agreeable is accessed as two separate morphemes, but because of the larger degree of orthographic and phonological overlap between agree and agreeable. Priming studies, such as Rueckl et al. (1997), have found that the amount of priming for suffixed words by their bases is a function of this degree of overlap. These results, though, run counter to those of Vannest and Boland (1999), in which no base frequency effect was found for words with the suffixes -ity and -ation, even for items in which no phonological change occurred in the base (e.g., taxation).

Regardless of the theoretical account, the relationship between the occurrence of the base frequency effect and the type of derivational suffix has been replicated across a variety of items. These results seem clearly to indicate a qualitative difference in processing between words with suffixes such as -able, -ness, and -less, which we will refer to as "decomposable" words, and those with -ity and -ation, which we will refer to as "whole-word" suffixed words. This distinction between suffix types, however, is not only a behavioral result but is also grounded in linguistic theory: For example, Kiparsky (1982) and Mohanan (1986) divided derivations into "levels" of word formation based on proximity to the root and interaction with phonological processes. Dual-route processing models attempt to take into account relevant linguistic variables and are able to account for much of the existing behavioral data, but such models do not make claims about the neural bases for the two processing routes.

Neuroscientific research on complex words has mainly focused on inflectional morphology rather than derived words. Several neuropsychological studies have found evidence for selective impairments to the processing of inflected words, and this evidence has been taken as support for the existence of a morphological processing system in the brain (see Badecker, Rapp, \& Caramazza, 1996; Niemi et al., 1994; Shapiro, Shelton, \& Caramazza, 2000). A detailed neuropsychological model of the processing of inflected words was proposed by Ullman et al. (1997), who concentrated on the difference between regular (e.g., walk, walked) and irregular (e.g., go, went) inflections. They examined patients with a variety of language deficits and, on the basis of the pattern of errors they observed, proposed a dissociation of lexical knowledge and gram- 
matical rules: The lexicon (access to irregular forms) corresponded to declarative memory and a medial temporal/ temporo-parietal circuit, and the rule system (computation of regular forms) corresponded to procedural memory and a frontal/basal ganglia circuit.

Inflection has been investigated in a few studies using functional neuroimaging. Laine, Rinne, Krause, Teras, and Sipila (1999) used PET to examine activation patterns as subjects memorized inflected versus monomorphemic nouns in Finnish, and they found greater activation in Broca's area for the inflected words. This result is consistent with behavioral and neuropsychological data from Finnish inflected words, in which decomposition effects generally appear. Also, Jaeger et al. (1996) conducted a PET study of English past tense, using a past tense production task and passive reading. Their results showed partially overlapping networks of left hemisphere areas activated for both regular and irregular past tense production versus reading, suggesting the possibility of separate systems for regular and irregular inflected forms (but see Seidenberg \& Hoeffner, 1998, and Ullman, 2001). Beretta et al. (2003) found differences using fMRI between regularly and irregularly inflected German words in a generation task: Irregular words showed a wider extent of activation than did regular words, but regular words showed more left-lateralized activation. All of these results suggest that neural activity associated with processing complex words may indeed be detectable using functional neuroimaging.

Derivational morphology, which is of interest here, has been the focus of only a few neuropsychological studies. For example, Badecker and Caramazza (1991) described a patient who made frequent errors in reading suffixed words (both inflections and derivations) and would substitute one affix for another when reading aloud. They suggested this patient's normal processing must have included a system for decomposing complex words. Ito, Sugioka, and Hagiwara (1996) found that Broca's aphasics had difficulty producing a regular derivational suffix in Japanese, but not irregular forms; for Wernicke's and transcortical aphasics, they found the opposite pattern. Hagiwara, Ito, Sugioka, Kawamura, and Shiota (1999) found a similar pattern of results with another set of Broca's aphasics: This group had difficulty producing a regular, productive derivational suffix but were more effective at producing a less productive, more idiosyncratic derivational suffix. The opposite pattern was found for Wernicke's patients and for those with Gogi aphasia (a type of anomic aphasia that preserves use of one of the Japanese writing systems). This pattern suggested a dissociation between regular and irregular suffixation, perhaps due to a decomposition process for the former.

In contrast with these neuroimaging and neuropsychological results, Davis, Meunier, and Marslen-Wilson (2004) found no effects of morphological structure in an event-related fMRI study. The participants in their study were asked to perform a semantic task, to judge whether or not each item in a trial was a synonym of the preceding item. Test items included monomorphemic and inflected verbs, monomorphemic nouns and adjectives, and nouns and adjectives with a variety of derivational suffixes. Davis et al. suggested that their results do not rule out the existence of neural mechanisms specific to morphological decomposition, but that they do raise the possibility of task-specific effects (which we will address in more detail in the Discussion section). In addition, Davis et al. did not narrow their analysis to predefined regions of interest (ROIs) such as those proposed by Ullman et al. (1997), and although they did take the important step of separating inflected and derived words, they did not distinguish derivational suffixes that do and do not show behavioral morphological effects.

We hypothesize that participants reading either inflected English words or derivationally suffixed English words that show evidence of decompositional processing (i.e., decomposable words with the suffixes -ness, -less, and-able) will show a pattern of activation suggesting that a morphological rule-based process is being used for access. This prediction about derivational suffixes has not been addressed in previous neuroimaging studies, but on the basis of data from Ullman et al. (1997) and others, we expect increased activation in Broca's/left inferior frontal gyrus and the basal ganglia, which Ullman and colleagues (Ullman, 2004; Ullman et al., 1997) have related to procedural memory for grammatical rules. For derivationally suffixed words in which decomposition effects do not occur (i.e., those formed with -ity or -ation), we do not expect this pattern.

The other component of the Ullman model, the declarative memory system, involves the medial temporal and parietal areas and is suggested to be involved in lexical retrieval of stored forms. If this suggestion is confirmed, it might indicate a double dissociation of those forms computed by morphological decomposition (which activate the procedural memory circuit) and those accessed as whole forms from the lexicon (which activate the declarative memory circuit). In fact, this double dissociation has been predicted in the context of a pasttense generation task, in which a base form is supplied to participants and they are asked to produce the past tense (e.g., Jaeger et al., 1998; Ullman et al., 1997). Because the base form is supplied, rule-based regular pasttense generation may indeed invoke procedural memory without significantly functionally requiring declarative memory, so that patients with damage to the declarative memory system could still perform the task. This task contrasts with irregular past tense generation, which necessarily requires retrieval of the irregular form. In an encoding or comprehension task such as the one we will describe below, however, lexical retrieval of words or morphemes takes place in all conditions. In the case of decomposable words, the base and suffix are accessed separately, but whole-word suffixed words and monomorphemics are retrieved as single units. Because the declarative memory circuit is engaged in both cases, dif- 


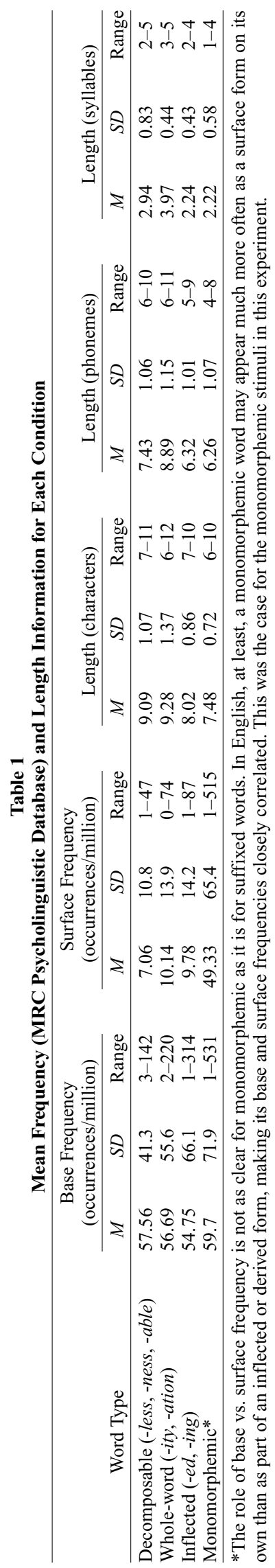

ferential activation of Ullman's declarative memory system is not predicted. Therefore, we concentrated in our experiment solely on the components of the procedural system as ROIs.

\section{METHOD}

\section{Subjects}

The subjects were 15 right-handed native speakers of English (8 females), ages $18-25$, with normal or corrected-to-normal vision and no history of reading disabilities or neurological disorders.

\section{Materials}

We used 100 decompositionally processed derived words (suffixes: -ness, -less, and -able), 100 whole-word processed derived words (suffixes: -ity and -ation), 100 inflected words (suffixes: -ed and -ing), and 100 monomorphemic words that were drawn from a number of syntactic categories: nouns, verbs, and adjectives. An effort was made to minimize ambiguity as to the category of the monomorphemic words, but about $25 \%$ of them could have been used in more than one syntactic category. Lists were matched as closely as possible for base and whole-word frequencies and number of letters; see Table 1. Because the presentation was visual, we concentrated on matching items for orthographic length. Therefore, items were not explicitly controlled for length in phonemes or syllables, but for completeness this information is also included in Table 1.

\section{Procedure}

We adopted a blocked design and encoding task previously used by Laine et al. (1999) with Finnish inflected words. The subjects viewed blocks of 50 words with a certain suffix type and were asked to remember them as well as possible. After each block of 50 words, the subjects were given a 10-item recognition test.

Words were presented for $2 \mathrm{sec}$ each with $500 \mathrm{msec}$ between words, in 22-point white characters on a black background on a screen at a distance of approximately 8 in. from the subjects' eyes. After the 50 words in the block were presented over approximately $2 \mathrm{~min}$, the recognition test instructions appeared for $10 \mathrm{sec}$. Then, randomly selected sets of 10 items, consisting of items from the preceding list and foil items that were not on the list, were presented to the subjects for a yes/no recognition buttonpress response. Presentation of recognition items was self-paced; a centered visual fixation cross was presented for $500 \mathrm{msec}$ between items. Block presentation order was pseudorandomized across subjects so that no subject saw two blocks of the same suffix condition consecutively.

\section{fMRI Methods}

This experiment was carried out at $3 \mathrm{~T}$ on a GE scanner at the University of Michigan fMRI center. We used a standard clinical quadrature radiofrequency head coil; foam padding was used to restrict head motion. Each imaging protocol began with a 10- to 15-min acquisition of images used for regional anatomy and T1weighted axial slices $(\mathrm{TR}=300 \mathrm{msec}, \mathrm{TE}=6.8 \mathrm{msec}, 160 \times 256$ matrix). Spiral imaging acquisition detected susceptibility-based (BOLD) contrast. Images were acquired with fat saturation (FOV = $24 \mathrm{~cm}$, flip angle $=60^{\circ}, 5-\mathrm{mm}$ slice thickness, 30-msec effective $\mathrm{TE}$, and a $64 \times 64$ matrix), resulting in a voxel size of $3.75 \times$ $3.75 \times 5 \mathrm{~mm}$ for functional activation. Spiral acquisitions consisted of 15 contiguous oblique slices obtained every second. Four spiral acquisition runs per subject included two encoding and corresponding recognition task blocks and lasted $6.5 \mathrm{~min}$ each.

\section{fMRI Data Analysis}

Data processing was carried out using the Interactive Data Language (IDL; Research Systems, Inc., Boulder, CO) and VoxBo software (www.voxbo.org). K-space data was reconstructed using a 
2-D FFT, with appropriate corrections for $N / 2$ ghost removal. Slice timing correction was performed through sync interpolation to align the acquisition times of all 15 slices to the same time point. Head movement correction was performed using automatic image registration (release 3.1; see Woods, Grafton, Holmes, Cherry, \& Mazziotta, 1998), which uses a rigid-body (6-parameter) model.

Analyses were carried out by applying statistical parametric mapping to the movement-corrected data. Voxelwise analysis was performed using the modified general linear model approach (Worsley \& Friston, 1995). Covariates included the four word-reading conditions of interest and the recognition test periods for each, as well as visual fixation. The data were passed through a low-pass filter to remove noise at the Nyquist frequency and a high-pass filter to remove noise at the lowest frequency (at which there was very little power in the experimental design). In order to impose a known amount of temporal autocorrelation in the data (which could then be accounted for), the data were smoothed in time by convolving them with a standard estimate of the hemodynamic response function (Aguirre, Zarahn, \& D'Esposito, 1998). To account for the fact that fMRI noise has more power at low than at high frequencies, a time domain representation of a $1 / f$ curve was placed within the $\mathrm{K}$ matrix (Worsley \& Friston, 1995; Zarahn, Aguirre, \& D'Esposito, 1997).

\section{Subject-by-Subject ROI Analysis}

We analyzed our data with a priori hypotheses about neuroanatomical ROIs in which we expected to see differences in levels of BOLD response for the different word-reading conditions. Spatially normalized group analyses, performed in many fMRI studies, depend on the assumption that the same functional brain area in different subjects gets mapped onto the same area in normalized space. If that assumption does not hold, then effects that are consistently observed in individual subjects could be missed in a group analysis. For example, if the contrast between decomposable and wholeword suffixed words elicited Broca's area activation in most individual subjects, that activation could be missed in a group analysis if Broca's area was not consistently mapped to the same area in normalized space across subjects. To address this concern, we focused our analysis to examine our ROIs in each subject. We did this by defining the basal ganglia (caudate, putamen, and globus pallidus) and Broca's area anatomically for each subject. We outlined Broca's area with a rather wide focus, including both the pars triangularis and pars opercularis of the inferior frontal gyrus, as well as contiguous areas of the anterior insula that have also been implicated in studies of language processing. ${ }^{2}$ Then, as a measure of BOLD response, we counted the number of voxels that were over a threshold of $t>2.5$ for each suffixed condition versus monomorphemic words. Computing such a measure for each of the conditions of interest required comparing those conditions against a common base- line, and for these analyses we used the monomorphemic words as the common baseline.

\section{Group ROI Analysis}

Although we were concerned that consistent patterns in our data might be obscured by spatial normalization of individual subjects' anatomies, we sought to support our individual subject measures with a group random-effects analysis. In this analysis, we could examine the direct contrasts between the different types of suffixed words in our two ROIs. First, two contrast images (made up of contrast $t$ values at each voxel) were created for each subject for both the decomposable $>$ whole-word and the inflected $>$ whole-word suffixed word blocks. Each subject's contrast images were normalized to a standard single subject's anatomy and were spatially smoothed with a kernel of $1.5 \times 1.5 \times 2$ voxels. Then, voxelwise $t$ tests across the group of 15 subjects were conducted on the $t$ values for each contrast.

\section{RESULTS}

\section{Behavioral Results}

There were no differences among any of the conditions in memory performance $(F=1.65, p=.19)$. Mean accuracies for blocks following each word condition ranged from $76 \%-83 \%$; these data are presented in Figure 1.

\section{fMRI Results}

As was previously discussed, we hypothesized that reading suffixed words for which we see evidence of decompositional processing in behavioral studies (-ness, -less, and -able words) will show a pattern of activation consistent with that for words with regular inflections (such as -ed). Broca's area/left inferior frontal gyrus and the basal ganglia should show increases in activity for these words, in contrast with derivationally suffixed words for which there are no behavioral decomposition effects (-ity and -ation words).

\section{Subject-by-Subject ROI Results}

Mean numbers of voxels for which $t>2.5$ for each suffixed word condition, using monomorphemic words as a common baseline, are presented in Figure 2 for the Broca's and basal ganglia ROIs. An ANOVA revealed a main effect of suffixed word condition (decomposable vs. whole-word vs. inflected) $[F(2,13)=10.65, p<.05]$

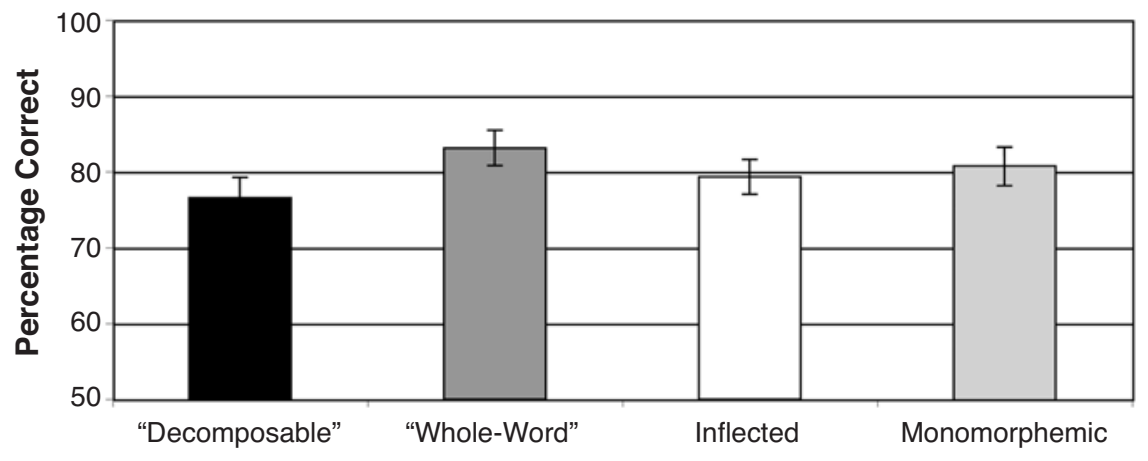

Figure 1. Recognition memory performance following blocks of each word condition. 




Figure 2. Number of voxels activated over threshold $\boldsymbol{t}>\mathbf{2 . 5}$ for each suffixed word condition versus monomorphemic words.

but no main effect of ROI (Broca's vs. basal ganglia; $F<$ $1.00, p>.50)$ nor any interaction of suffixed word condition and ROI $(F<1.00, p>.50)$. Planned comparisons revealed that the decomposable $>$ monomorphemic contrast activated more voxels over threshold than did the whole-word $>$ monomorphemic contrast $[t(14)=4.85$, $p<.01]$, and so did the inflected $>$ monomorphemic contrast, if marginally $[t(14)=1.90, p=.07]$.

\section{Group ROI Results}

Axial slices, presented with group functional data overlaid on an individual subject's normalized anatomy, are presented in Figure 3 for each of the contrasts between the suffixed word conditions. In Broca's area-delineated as the posterior part of the inferior frontal gyrus, BA 45/45, and contiguous areas of the insula - there were no voxels over a $t$ threshold of 2.5 in any of the contrasts between the suffixed word conditions. In our basal ganglia ROI, however, there were five contiguous voxels in the left caudate nucleus that had $t>2.5$ for decomposable versus whole-word processed words (Figure 3A; MNI coordinates of max voxel: $x=-1.88, y=+5.63, z=0)$. For inflected versus whole-word processed words, there were three contiguous voxels with $t>2.5$ in the left caudate nucleus and two additional suprathreshold voxels that were slightly superior to those three by one intervening 5-mm slice, plus one voxel with $t>2.5$ in the right caudate nucleus (Figure 3B; MNI coordinates of max voxel: $x=-1.88, y=+5.63, z=+5.00)$. These results are in part consistent with our voxel-counting measure on individual subjects, as well as with the predictions of the declarative/procedural model of processing complex words. Although no differences between suffixed conditions were detected in Broca's area, results were as predicted in the basal ganglia: Those words that show decomposition effects show increases in activity.

\section{Activation in Other Brain Areas}

After correcting for multiple comparisons, we did not observe any significant activations in brain areas outside of our Broca's area and basal ganglia ROIs for any of the relevant contrasts between suffixed word types.

\section{DISCUSSION}

Dual-route models of processing complex words suggest that some suffixed words are processed by decomposition into component morphemes and that others are not, depending on linguistic properties. Neuropsychological studies of complex words (Ullman et al., 1997) have associated morpheme-by-morpheme processing of suffixed words with Broca's area and the basal ganglia as part of a procedural memory circuit. (The basal ganglia are often associated with memory for sequences in nonlinguistic tasks, which is similar to combining sequences of morphemes.) We therefore predicted that suffixed words processed decompositionally would show increases in neural activity in these regions. The fMRI data we have presented support such a model. Reading words with derivational suffixes in English for which we see decomposition effects in behavioral studies (-ness, -less, and -able words) showed a pattern of activation consistent with that for words with regular inflections (-ed and -ing words). Both of these tasks showed increases in activity in the ROIs relative to suffixed words not processed via decomposition (-ity and -ation words). Thus, not only are these results consistent with behavioral data, they support in a novel way the specific predictions of an existing model of linguistic processing in the brain.

Although regularly and irregularly inflected words have been at the center of the debate regarding complex word processing, derived words offer an additional, and perhaps better controlled, testing ground for dual-route models. Inflections such as past tense have a clear default suffix form; their irregular forms are exceptional and do not appear to involve addition of a suffix (but see Halle \& Marantz, 1993, for an alternative account). This exceptional status may explain the overall larger extent of activation found for irregular forms in both Jaeger et al.'s (1998) and Beretta et al.'s (2003) studies. In con- 

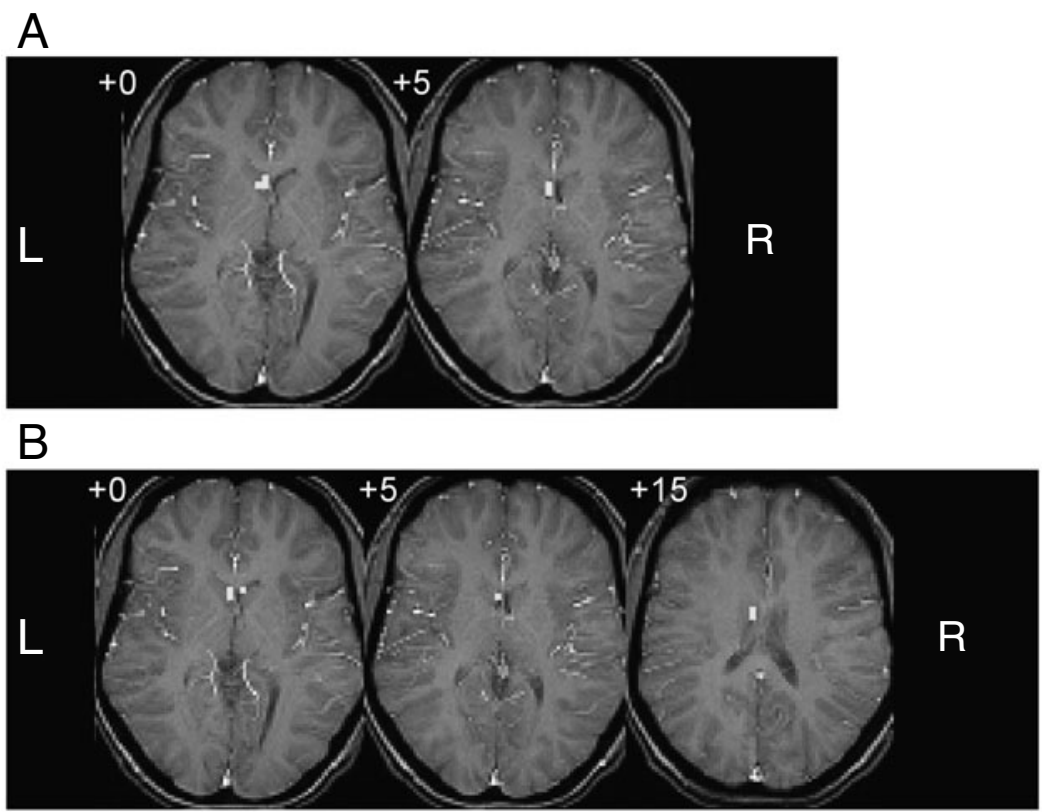

Figure 3. (A) Basal ganglia ROI analysis of decomposable $>$ whole-word contrast in 15 subjects, viewed on two contiguous axial slices of an individual subject's anatomy. Voxels pictured in yellow are those over threshold $t>2.5$. (B) Basal ganglia ROI analysis of inflected $>$ whole-word contrast in 15 subjects, viewed on three axial slices of an individual subject's anatomy. Voxels pictured in yellow are those over threshold $t>2.5$.

trast, the two types of derived words investigated here are not in a default/exception relationship, and both involve addition of an overt suffix. The two groups of derived words were matched as carefully as possible and differed only in the type of suffix they included. Interestingly, the increases in activation associated with morphological decomposition in our subject-by-subject analysis were greater for the decomposable than for the inflected words. Although this difference was not significant, we can speculate that activation levels may have been affected by properties of the two suffix types. The base and surface frequencies of the stimulus words were matched, but derivational suffixes themselves occur less frequently than inflections do. Accessing a less frequent morpheme as part of the decomposition process may have resulted in increases in activation; in fact, language processing regions have been found to be sensitive to lexical frequency (Fiez, Balota, Raichle, \& Petersen, 1999; Keller, Carpenter, \& Just, 2001).

Also, these results were found for the visual modality and may not completely generalize to auditory presentation. In the visual modality, information about base forms and suffixes is presented simultaneously, whereas in the auditory modality, a base occurs earlier in time than a suffix. This difference suggests that there would be an even greater influence of base frequency on suffixed words and an increased role of phonological interaction between base and suffix in the auditory modality, although these issues have not been explored in great de- tail (but see Wurm, 1997, for an examination of auditory processing of prefixed words).

More robust effects of morphological structure may be detected with future sets of stimulus materials. Behavioral morphological effects have been found most consistently for words for which the frequency of the base morpheme is high relative to that of the surface form (see Hay, 2000) and for which the surface form frequency is low overall. (Alegre \& Gordon, 1999, have suggested that words with surface form frequencies greater than 6 occurrences per million are accessed as full forms.) Our stimulus items were matched for base and surface frequencies across conditions, and included a range of both frequency measures. Consequently, the ratio of base to surface frequency varied among the items in each suffixed word condition, and not all of the suffixed words were extremely low in surface form frequency (although more than $50 \%$ of the suffixed words had a surface frequency of 6 per million or lower). According to some dual-route models (e.g., Alegre \& Gordon, 1999), some complex words may have been accessed as full forms under these conditions. It may also be that a language with a more complex morphological system would show different morphological effects in both behavior and neural activation (see Vannest et al., 2002, for a behavioral comparison between English and Finnish).

The results of Davis et al. (2004), who found no differences in activation based on the morphological structure of words, emphasized the possibility of task-specific ef- 
fects in investigations of morphological processing. Davis et al. made use of a semantic judgment task for equal numbers of simple and complex words (although they did note that behaviorally, morphological effects have been found in similar tasks). A memory encoding task that includes a large number of suffixed words, such as the one in the present study, may draw particular attention to the morphological structure of the items, making morphological decomposition more likely. Despite this difference in methods, however, differences between decomposable and whole-word suffixed words still emerged. Previous findings examining inflected words (Beretta et al., 2003; Jaeger et al., 1998) made use of a generation task in which the base form was provided to subjects and they responded with the inflected form. Such a task seems even more likely to draw attention to the morphological structure of words in a way that may not be similar to normal processing. As mentioned above, such a generation task leads to different predictions for the brain regions involved in the declarative/procedural model than does the encoding task. We concur with Davis et al., who emphasized the importance of taking into account taskspecific differences and patterns of behavioral data in morphological processing. Comparisons across tasks using the same complex word stimuli are needed to clarify the roles of the subcomponents of the declarative and procedural memory systems in both the comprehension and production of complex words.

In the context of previous neuroscientific work on complex words (e.g., Laine et al., 1999; Ullman et al., 1997), the present study extends the range of findings to derived words. Both behavioral and neuropsychological evidence support a dual-route, declarative/procedural model in which not all complex words are processed identically and in which the processing system is sensitive to subtle differences in the regularities found in the structure of words.

\section{REFERENCES}

Aguirre, G. K., Zarahn, E., \& D'Esposito, M. (1998). The variability of human, BOLD hemodynamic responses. NeuroImage, $\mathbf{8}, 360$ 369.

Alegre, M., \& Gordon, P. (1999). Frequency effects and the representational status of regular inflections. Journal of Memory \& Language, 40, 41-61.

BaAyen, R. H., DiJkstra, T., \& Schreuder, R. (1997). Singulars and plurals in Dutch: Evidence for a parallel dual-route model. Journal of Memory \& Language, 37, 94-117.

BADECKER, W., \& CARAMAZZA, A. (1991). Morphological composition in the lexical output system. Cognitive Neuropsychology, 8, 335-367.

BADECKER, W., RAPP, B., \& CARAMAZZA, A. (1996). Lexical morphology and the two orthographic routes. Cognitive Neuropsychology, 13, 161-175.

Beretta, A., Campbell, C., Carr, T., Huang, J., Schmitt, L., ChrisTIANSON, K., \& CAO, Y. (2003). An ER-fMRI investigation of morphological inflection in German reveals that the brain makes a distinction between regular and irregular forms. Brain \& Language, $\mathbf{8 5}$, $67-92$.

BERTRAM, R., Schreuder, R., \& BAAYEN, R. H. (2000). The balance of storage and computation in morphological processing: The role of word formation type, affixal homonymy, and productivity. Journal of
Experimental Psychology: Learning, Memory, \& Cognition, 26, 489511.

BRADLEY, D. (1980). Lexical representation of derivational relation. In M. Aronoff \& M.-L. Kean (Eds.), Juncture (pp. 37-55). Saratoga, CA: Anma Libri.

Caramazza, A., Laudanna, A., \& Romani, C. (1988). Lexical access and inflectional morphology. Cognition, 28, 297-332.

Davis, M., Meunier, F., \& MarsLen-Wilson, W. (2004). Neural responses to morphological, syntactic, and semantic properties of single words: An fMRI study. Brain \& Language, 89, 439-449.

Fiez, J. A., Balota, D. A., Raichle, M. E., \& Petersen, S. E. (1999). The effects of word frequency and spelling-to-sound consistency on the functional anatomy of reading. Neuron, 24, 205-218.

Hagiwara, H., Ito, T., Sugioka, Y., Kawamura, M., \& Shiota, J. (1999). Neurolinguistic evidence for rule-based nominal suffixation. Language, 75, 739-763.

Halle, M., \& Marantz, A. (1993). Distributed morphology and the pieces of inflection. In K. Hale \& S. J. Keyser (Eds.), The view from Building 20: Essays in linguistics in honor of Sylvain Bromberger (pp. 111-176). Cambridge, MA: MIT Press.

HAY, J. (2000). Causes and consequences of word structure. Unpublished doctoral dissertation, Northwestern University.

Ito, T., Sugioka, Y., \& Hagiwara, T. (1996). Psychological status of rules in derivational morphology: Evidence from Japanese nominal suffixation. Metropolitan Linguistics, 16, 18-30.

Jaeger, J., Lockwood, A., Kemmerer, D., Van Valin, R., JR., MurPHY, B., \& KHalaK, H. (1996). A positron emission tomographic study of regular and irregular verb morphology in English. Language, 72, 451-497.

JAEGER, J., VAN VALIN, R., JR., \& LockWOOD, A. (1998). Response to Seidenberg and Hoeffner. Language, 74, 123-128.

Joanisse, M. F., \& Seidenberg, M. S. (1999). Impairments in verb morphology after brain injury: A connectionist model. Proceedings of the National Academy of Sciences, 96, 7592-7597.

Keller, T. A., Carpenter, P. A., \& JUST, M. A. (2001). The neural bases of sentence comprehension: A fMRI examination of syntactic and lexical processing. Cerebral Cortex, 11, 223-237.

KIPARSKY, P. (1982). Lexical morphology and phonology. In I.-S. Yang (Ed.), Linguistics in the morning calm (pp. 3-91). Seoul: Hanshin. Laine, M., Rinne, J., Krause, B., Teras, M., \& Sipila, H. (1999). Left hemisphere activation during processing of morphologically complex word forms in adults. Neuroscience Letters, 271, 85-88.

Mohanan, K. (1986). The theory of lexical phonology. Dordrecht: Reidel. Niemi, J., Laine, M., \& TuOMInen, J. (1994). Cognitive morphology in Finnish: Foundations of a new model. Language \& Cognitive Processes, 9, 423-446.

RAVEH, M. (2002). The contribution of frequency and semantic similarity to morphological processing. Brain \& Language, 81, 312-325.

RueckL, J. G., Mikolinski, M., Raveh, M., Miner, C. S., \& Mars, F. (1997). Morphological priming, fragment completion, and connectionist networks. Journal of Memory \& Language, 36, 382-405.

RuECKL, J. G., \& RAVEH, M. (1999). The influence of morphological regularities on the dynamics of a connectionist network. Brain \& Language, 68, 110-117.

SCHREUDER, R., \& BAAYEN, R. H. (1995). Modeling morphological processing. In L. Feldman (Ed.), Morphological aspects of language processing (pp. 131-154). Hillsdale, NJ: Erlbaum.

SeidenberG, M. S., \& Gonnerman, L. M. (2000). Explaining derivational morphology as the convergence of codes. Trends in Cognitive Sciences, 4, 353-361.

SeIDENBERG, M. S., \& Hoeffner, J. H. (1998). Evaluating behavioral and neuroimaging data on past tense processing. Language, 74, 104122.

Shapiro, K., Shelton, J., \& CARAmazza, A. (2000). Grammatical class in lexical production and morphological processing: Evidence from a case of fluent aphasia. Cognitive Neuropsychology, 17, 665-682.

TAFT, M. (1979). Recognition of affixed words and the word frequency effect. Memory \& Cognition, 7, 263-272.

Ullman, M. T. (2001). The declarative/procedural model of lexicon and grammar. Journal of Psycholinguistic Research, 30, 37-69. 
Ullman, M. T. (2004). Contributions of memory circuits to language: The declarative/procedural model. Cognition, 92, 231-270.

Ullman, M. [T.], Corkin, S., Coppola, M., HickoK, G., Growdon, J. H., Koroshetz, W. J., \& Pinker, S. (1997). A neural dissociation within language: Evidence that the mental dictionary is part of declarative memory, and that grammatical rules are processed by the procedural system. Journal of Cognitive Neuroscience, 9, 266-276.

VAnNest, J., Bertram, R., JARVIKIVI, J., \& Niemi, J. (2002). Counterintuitive cross-linguistic differences: More morphological computation in English than in Finnish. Journal of Psycholinguistic Research, 31, 83-106.

VANNEST, J., \& BolAND, J. (1999). Lexical morphology and lexical access. Brain \& Language, 68, 324-332.

Woods, R. P., Grafton, S. T., Holmes, C. J., Cherry, S. R., \& MaZZIOTTA, J. C. (1998). Automated image registration: I. General methods and intrasubject, intramodality validation. Journal of Computer Assisted Tomography, 22, 139-152.

WORSLEY, K. J., \& FrISTON, K. J. (1995). Analysis of fMRI time series revisited-again. NeuroImage, 2, 173-181.
Wurm, L. (1997). Auditory processing of prefixed English words is both continuous and decompositional. Unpublished manuscript. SUNY, Stony Brook.

Zarahn, E., Aguirre, G. K., \& D’Esposito, M. (1997). Empirical analyses of BOLD fMRI statistics: I. Spatially unsmoothed data collected under null-hypothesis conditions. NeuroImage, 5, 179-197.

\section{NOTES}

1. Cross-linguistic studies have suggested that phonological interaction may not be the only relevant factor affecting the balance between morphological decomposition and full-form lexical access. See Baayen, Dijkstra, \& Schreuder, (1997), Bertram et al. (2000), and Vannest et al. (2002) for evidence of effects of productivity, affix ambiguity, and cross-linguistic differences.

2. Note that our choice of ROIs was intended to detect differences in the procedural memory system, which may vary between subjects in its precise anatomical mapping. Our goal was not to delineate functions of possible subdivisions of Broca's area.

\section{APPENDIX \\ Items Presented in Encoding Task}

\section{"Decomposable" Words}

accountable, adaptable, admirable, advisable, allowable, aptness, baldness, bitterness, boundless, breathless, brightness, callousness, calmness, comfortable, commendable, comparable, conceivable, coolness, countless, coyness, creditable, dauntless, debatable, deplorable, desirable, detachable, detectable, dreamless, dryness, dullness, emptiness, endurable, enjoyable, enviable, excusable, expendable, fairness, fashionable, faultless, featureless, fitness, flatness, fondness, freshness, fruitless, gentleness, greenness, grimness, guileless, guiltless, hammerless, heedless, holiness, idleness, meaningless, merciless, mirthless, narrowness, nerveless, noiseless, noticeable, obtainable, painless, pardonable, passable, peerless, penniless, pitiable, pitiless, predictable, preferable, prettiness, priceless, printable, profitable, punishable, regardless, regrettable, relentless, reliable, remarkable, remorseless, seamless, shapeless, shiftless, sickness, sinless, sizable, speechless, spineless, spotless, stainless, suitable, tasteless, thickness, toneless, traceable, weakness, weariness, worthless

\section{"Whole-Word" Words}

ability, accusation, acidity, adaptation, admiration, adoration, adversity, affirmation, agility, alienation, alteration, antiquity, aspiration, brutality, cancellation, centrality, chastity, civility, coloration, combination, commendation, commutation, compilation, complexity, computation, condemnation, consultation, convexity, curiosity, curvation, density, deprivation, derivation, divination, divinity, electricity, equality, examination, expectation, expiration, explanation, extremity, falsity, fatality, fertility, fluidity, formality, futility, hostility, humidity, imagination, immunity, inspiration, intensity, invitation, legality, limitation, liquidation, liquidity, lucidity, maturation, maturity, mentality, minority, mobility, modernity, morality, nobility, nudity, obesity, observation, orientation, plantation, plasticity, profanity, provocation, pulsation, quotation, rapidity, recitation, regality, regularity, relaxation, retardation, revelation, rigidity, rotundity, salutation, sanity, scarcity, seniority, severity, solidity, stability, stupidity, temptation, validity, visitation, vitality, vulgarity

\section{Inflected Words}

advanced, affected, anchoring, bending, blessing, blooming, boarding, boiling, bottled, branched, branded, browsing, buttoned, catching, cheered, clotted, coasted, coating, collected, commanding, cornered, crackled, creeping, dilated, doubling, drilling, fancied, fielded, figured, filling, filtering, finished, finishing, flashing, flooding, flowering, frosted, galloping, glimmering, grasping, greeting, grinding, grounding, guarded, handled, hatching, kissing, knocking, knuckled, lending, lifting, loading, lodging, mourning, nestling, painted, perplexed, planting, polishing, punching, rambling, rattling, scattering, scorched, scoring, scrambling, scrubbed, seating, settling, shadowing, sleeping, slipped, smelling, smoothing, sneaking, sneezing, soaking, sparkling, sprinkling, stacking, stamping, starched, steering, storming, swelling, swimming, switching, thumping, thundering, tormenting, touched, twinkling, visiting, weathering, whirling, wintered, withered, worried, yellowed, yielding 


\section{APPENDIX (Continued)}

\section{Monomorphemic Words}

absolute, abstract, accident, accomplish, achieve, address, advance, alcohol, aluminum, amateur, antenna, apparatus, attitude, attorney, beneath, brilliant, brother, calendar, captain, capture, challenge, chlorine, circuit, college, comment, compete, complete, concept, concert, correct, crocodile, daughter, delicate, destroy, dilemma, discipline, divorce, doctrine, element, engine, envelope, exhibit, extreme, fiction, fluoride, furnish, genteel, genuine, gesture, harness, harvest, hundred, husband, incident, juvenile, kitchen, leprosy, mackerel, message, minstrel, morphine, mustard, orchestra, pamphlet, parsley, perfect, promise, province, purchase, quarrel, racquet, rampant, relevant, remnant, sabotage, schnapps, shampoo, sheriff, splendid, stadium, stomach, straight, strange, strength, stretch, struggle, stubborn, substance, success, surface, syringe, tangent, textile, thought, traffic, tribute, trouble, urethane, warrant, weather

(Manuscript received October 15, 2003;

revision accepted for publication September 30, 2004.) 